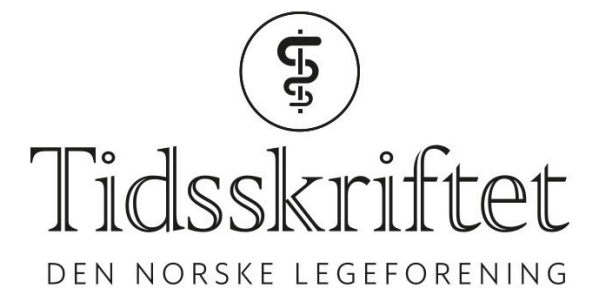

DEN NORSKE LEGEFORENING

\title{
Unødvendig polarisert debatt
}

KOMMENTAR

\section{KRISTIN A. BAKKE}

E-post: kristinb@ous-hf.no

Kristin A. Bakkeer overlege ved NevSom, Nasjonalt kompetansesenter for Nevroutviklingsforstyrrelser og hypersomnier.

Ingen oppgitte interessekonflikter.

\section{EGIL MIDTLYNG}

Egil Midtlyng er psykologspesialist ved NevSom, Nasjonalt kompetansesenter for Nevroutviklingsforstyrrelser og hypersomnier.

Oppgitte interessekonflikter: Egil Midtlyng var medlem av redaksjon for: ADHD/Hyperkinetisk forstyrrelse - Nasjonal faglig retningslinje for utredning, behandling og oppfølging

Vogt \& Lunde setter spørsmålstegn ved helsetjenestens oppfølging og forståelse av barn og unge med $\mathrm{AD} / \mathrm{HD}$, og de hevder at det er en kunnskapskrise.

Det er viktig å stille kritiske spørsmål til klinisk praksis, men er kunnskapsgrunnlaget rundt AD/HD så mye dårligere enn for andre tilstander? Debatten om AD/HD kan bli unødvendig polarisert uten at dette gagner pasientene. Risiko for overdiagnostisering og overbehandling diskuteres for mange medisinske tilstander (1).

Data fra reseptregisteret viser at andelen barn som har fått utlevert et sentralstimulerende legemiddel har holdt seg relativt stabil fra 2010 og frem til i dag (2). Økningen i medikamentell behandling de senere år skyldes primært at flere voksne behandles for $\mathrm{AD} / \mathrm{HD}$.

Diagnosen $\mathrm{AD} / \mathrm{HD}$ krever at kjernesymptomene er mer uttalte enn forventet ut fra alder, og at funksjonsnivå er signifikant nedsatt. Symptomer som ligner AD/HD, har vært beskrevet $\mathrm{i}$ medisinsk litteratur i mer enn 200 år. Det biologiske grunnlaget for $\mathrm{AD} / \mathrm{HD}$ varierer hos ulike personer, og det er stor grad av arvelighet (3). AD/HD er en nevroutviklingsforstyrrelse, og det kan forklare hvorfor barn født sent på året har økt risiko for å få diagnosen: Barna sammenlignes med eldre klassekamerater. Kanskje er det et argument for at det burde bli lettere for enkelte å få tilpasset skolestart?

Korttidsstudier har dokumentert at legemiddelbehandling er effektivt mot AD/HD, men hvor lenge bør studiene vare for å kunne forsvare langvarig behandling? Randomiserte kontrollerte studier med varighet over ett år er vanskelig å gjennomføre. Der det ikke foreligger kontrollerte langtidsstudier, skal en da slutte med korttidsbehandling som viser signifikant effekt? MTA-studien viste klar effekt av legemiddelbehandling ved 14-måneders oppfølging. Etter dette ble kontrollen opphevet og behandlingsgruppene blandet.

Ikke-medikamentell behandling skal alltid forsøkes først. Dersom barn står på medikamenter i årevis uten at dette evalueres, slik forfatterne hevder, er det ikke i tråd med 
gjeldende retningslinje. I den står det at det kan være vanskelig å vurdere effekten av langtidsbehandling, og det anbefales nøye oppfølging med minst halvårlige kontroller for å sjekke om pasienten fortsatt har nytte av behandlingen og mulige bivirkninger.

Diskusjonen av legemiddeleffekt må ikke forveksles med spørsmål om helsetjenestens organisering av behandling. En utfordringen er ansvarfordelingen mellom fastleger og spesialisthelsetjeneste om behandling tilpasset den enkelte. Barnet kan følges opp av fastlege dersom medisinene har gunstig effekt og tilstanden er stabil på behandling. Spørsmålet er: Når kan man si at et barn med AD/HD som er i utvikling, er stabilisert på behandling?

\section{LITTERATUR:}

1. McCaffery KJ, Jansen J, Scherer LD et al. Walking the tightrope: communicating overdiagnosis in modern healthcare. BMJ 2016; 352: i348. [PubMed][CrossRef]

2. Ørstavik R, Gustavson K, Rohrer-Baumgartner N et al. ADHD Norge. En statusrapport. Rapport 2016: 4. Oslo: Folkehelseinstituttet, 2016.

3. Faraone SV, Asherson P, Banaschewski T et al. Attention-deficit/hyperactivity disorder. Nat Rev Dis Primers 2015; 1: 15020. [PubMed][CrossRef]

Publisert: 16. mars 2018. Tidsskr Nor Legeforen. DOI: 10.4045/tidsskr.18.0186

(C) Tidsskrift for Den norske legeforening 2020. Lastet ned fra tidsskriftet.no 